\title{
Išqalyūla, no Ašqīlūla: el nombre correcto de la familia fundadora del Emirato Nazarí
}

\section{Išqalyūla, not Ašqīlūla: the correct name of the founding family of the Nasrid Emirate}

\author{
Josef ŽENKA \\ Universidad Carolina de Praga \\ josef.zenka@ff.cuni.cz
}

Recibido: 17 de marzo de 2014

Aceptado: 24 de mayo de 2014

\section{RESUMEN:}

En este artículo se estudia el nombre correcto de la familia Išqalyūla, una de las familias fundadoras del Emirato Nazarí de Granada que ha sido hasta ahora llamada Ašqīlūla, a pesar de haber demostrado María Jesús Rubiera Mata que dicho nombre se debería considerar incorrecto. En este estudio, basándonos en el análisis de una inscripción funeraria y de varios manuscritos, desarrollaremos su teoría. En las fuentes, el nombre de la familia aparece principalmente bajo la forma en que lām precede a $y \bar{a}{ }^{\prime}$. La mención más antigua se halla en la lápida funeraria de Alī Ibn Išqalyūla, elaborada después de su muerte. Este artículo muestra también que algunos de los manuscritos vocalizan esta palabra como Išqalyūla, pero nunca como Ašqīlūla. Por lo tanto, se deduce que esta segunda forma es un neologismo creado por autores modernos, que se acercaron a la palabra con la misma imprecisión que ciertos autores antiguos y copistas de las obras. Mediante la comparación de textos de diferentes manuscritos, el proceso de cambio del nombre de la forma Išqalyūla a Išqaylūla se revela y se explica como un error o confusión de los escribanos. La conclusión final es que el nombre correcto es Išqalyūla, transcripción fiel de la palabra Escallola/Escalhola.

Palabras clave: Išqalyūla, Ašqīlūla, Nazaríes, manuscritos, Escallola, Rubiera Mata.

\begin{abstract}
:
This article is concerned with the correct form of the name of Išqalyūla's family. One of the founding father's families of the Nasrid Emirate has so far been named Ašqīlūla, even though María Jesús Rubiera Mata has proven that this name should be considered incorrect. This study develops her theory further. Based on the analysis of the funeral inscription and manuscripts, the most important ones being from 14th century Granada. This confirms that the sources mainly bear the name in the form where lām is preceeding $y \bar{a}$ ”. It could first be seen in the unique epitaph of 'Alī Ibn Išqalyūla made after his death. In addition, the article shows that some of the manuscripts are vocalized in the form of Išqalyūla but none as Ašqīlūla. It therefore demonstrates that the latter is a neologism coined by modern authors approaching the word with the same misunderstanding held by antique authors and copyists. From textual comparison with other manuscripts, the change of the name from the Išqalyūla form to Išqaylūla is described and explained as a scribe's mistake. The final conclusion is that the correct name was Išqalyūla which was a transcription of the word Escallola/Escalhola.
\end{abstract}

Keywords: Išqalyūla, Ašqīlūla, Nasrids, Manuscripts, Escallola, Rubiera Mata. 
La familia Išqalyūla (Escallola) fundó, junto con la familia Nazarí, el emirato nazarí de Granada. ${ }^{1}$ Hasta el momento de su partida sin retorno al norte de África jugó siempre un importante papel tanto en la formación territorial del emirato como en la configuración de su poder. Fue, por lo que se refiere a su estatuto personal, la única familia considerada por la de los Nazaríes como su igual, hecho que se ve avalado por el intercambio mutuo de matrimonios al máximo nivel durante al menos dos generaciones. ${ }^{2}$ Ya dos autores granadinos, Ibn al-Jațī ${ }^{3}$ y al-Bunnāh $\overline{1}^{4}$, se mostraron conscientes de la posición excepcional de esta familia. También lo consideró así Ibn Jaldūn, a juzgar por lo que observamos en su concepto de Historia basado en 'așabīya. ${ }^{5}$ En general, ni su posición ni su papel han pasado desapercibidos para nadie, incluyendo a los historiadores y arabistas modernos, quienes, desde los inicios de la investigación científica sobre la Granada Nazarí en el siglo XIX hasta nuestros días, han tratado de encontrar el significado del nombre de la familia para, desde diferentes perspectivas, interpretar su papel, ya indagando en la división de poder, ya en la composición de las estructuras sociales o ya pasando por el estudio de las relaciones con los Meriníes, etc. ${ }^{6}$ Sin embargo, puede decirse que no es sólo el significado del nombre de la familia lo que no ha estado claro desde el principio, sino incluso su mera transcripción, que a menudo se ha mostrado vacilante. Ha oscilado ésta entre las formas Axkilyola, ${ }^{7}$ Ašqalyūla, ${ }^{8}$ Achqîloûla, ${ }^{9}$ Ašḳ̂ilūla ${ }^{10}$, Išqaylūla, ${ }^{11}$ el

\footnotetext{
${ }^{1}$ El artículo forma parte del Proyecto de Investigación número 13542/2013 financiado por Fundación científica de la Universidad Carolina que se desarrolla en la Facultad de Letras de UK.

${ }^{2}$ En particular, cabe mencionar el matrimonio de la madre del primer emir de Granada con Yūsuf alAhmar, así como los enlaces de las dos hijas de Muhammad I con los descendientes de Abū l-Ḥasan Išqalyūla.

${ }^{3}$ Sobre todo en sus obras al-Ihāta fì ajbār $\dot{G} a r n \bar{a} t a$ y A'māl al-a 'lām.

${ }^{4}$ En su obra al-Iklīl fì tafḍ̂ll al-najīl.

${ }^{5}$ IBN JALDŪN, ‘Abd al-Raḥmān, Muqaddima Ibn Jaldūn, ed. Ḥāmid Aḥmad al-Ṭāhir, al-Qāhira 2004, 214-215.

${ }^{6}$ Para una bibliografía sobre este asunto véase VIDAL CASTRO, Francisco, “Frontera, genealogía y religión en la gestación y nacimiento del Reino Nazarí de Granada: En torno a Ibn al-Aḥmar”, en III Estudios de Frontera: Convivencia, defensa y comunicación en la Frontera, Francisco Toro Ceballos José Rodriguez Molina (coords.), Jaén, 2000, 808-809, n. 50; BOLOIX GALLARDO, Bárbara, De la taifa de Arjona al reino nazarí de Granada (1232-1246): En torno a los orígenes de un estado y de una dinastía, Jaén 2005, 131-137; GARCÍA FITZ, Francisco, “Alfonso X, el Reino de Granada y los Banū Ašqīlūla: Estrategias políticas de disolución durante la segunda mitad del siglo XIII”, en Anuario de Estudios Medievales 27 (1997) 216-237.

${ }^{7}$ LAFUENTE ALCÁNTARA, Emilio, Inscripciones Árabes de Granada, precedidas de una reseña histórica y de la genealogía detallada de los reyes Alahmares, Madrid 1859, 22, 64.

${ }^{8}$ MÜLLER, Marcus, Beiträge zur Geschichte der Westlichen Araber: I Heft, München 1866, 116. En el segundo lugar la transliteró y vocalizó como Išqalyūla. Ibidem, 118.

${ }^{9}$ Esta forma utilizaron los autores en volumen de Archives Marocaines sobre Alcazarquivir. MICHAUX-BELLAIRE, E. y SALMON, G., "El-Qçar El-Kebir: Une ville de province au Maroc septentrional”, en Archives Marocaines II, 2 (1904) 153, 177, 178, 204.

${ }^{10}$ ALLOUCHE, I. S., "La révolte des Banū Ašḳīlūla contre le sultan Nașrīte Muhammad II d’aprés le kitāb a māl al-a 'lām d'Ibn al-Huațīb", en Hespéris XXV (1938) 1-11. El texto editado de LéviProvençal en el que se basa esta traducción la familia se transcribe y vocaliza como Ašqīlūla. IBN AL-
} 
castellano Escallola ${ }^{12} \mathrm{o}$ el gallego-portugués Escalhola ${ }^{13}$. Tan sólo en los últimos años se ha fijado generalmente la forma Ašqīlūla.

Este inesperado problema con la transcripción del nombre de la familia en cuestión surgió mientras preparaba un estudio sobre varios folios inéditos de un manuscrito del segundo volumen de la crónica de Ibn al- Jațīb 'Amāl al-ā' lām. ${ }^{14}$ En él, el nombre de la familia aparece principalmente bajo la forma en que lām precede a $y \bar{a}$ '. Asimismo, teniendo en cuenta que el copista de tal manuscrito lo menciona así hasta en dos lugares ${ }^{15}$, persistiendo en el uso de esta forma o de sus derivaciones, ${ }^{16}$ me planteé la pregunta de cómo debía ser realmente transcrito el nombre (de si se trataba de un error o de si se podía averiguar cuál de las dos formas es la correcta). Tenía entonces a mi disposición Les Inscriptions Arabes d'Espagne de Lévi-Provençal, una de las cuales pertenece a un miembro de esta familia, ${ }^{17}$ así como mi copia personal del manuscrito 1653 del Monasterio San Lorenzo de El

JAṬ̂̄B, Lisān al-Dīn, Ta'rīj Isbānīya al-Islāmīya aw Kitāb a 'māl al-a 'lām fì man būyi a qabla ihtilām min mulūk al-islām, ed. E. Lévi-Provençal, al-Qāhira 2002, 287-291.

${ }^{11}$ IBN AL-JAṬĪB, Lisān al-Dīn, al-Iḥạta fì ajbār Garnāta, ed. Muḥammad 'Abd Allāh 'Inān, alQāhira 2001, vol. I, 342, 564, vol. III, 378, 382.

${ }^{12}$ RUBIERA DE EPALZA, María Jesús, "Los Banū Escallola, la dinastía granadina que no fue”, en Andalucía Islámica 2 (1981-82) 85-86. El más antiguo historiador que menciona la familia valiéndose del nombre Escallola fue Geronymo Gudiel y no Gonzalo Argote de Molina. Véanse: GUDIEL, Geronymo, Compendio de algunas historias de España, donde se tratan muchas antiguedades dignos de memoria y especialmente se da noticia de la Antigua familia de los Girones, y de otros muchos linajes, Alcala 1577, 32; ARGOTE DE MOLINA, Gonçalo, Nobleza de Andaluzia, Sevilla 1588, 89. Realmente Gudiel y Argote de Molina relatan un episodio descrito en el libro de linajes del conde Pedro, Os Livros de Linhagens, en Portvgaliae Monvmenta Historica: Scriptores, Olisipone 1860, volumen II, Fasciculus II, 270.

${ }^{13}$ Os Livros de Linhagens, 270. RUBIERA DE EPALZA, María Jesús, "Los Banū Escallola", 9091. Es inexacta la afirmación de Boloix Gallardo, quien dice: "Es digno de resaltar que esta familia es referida en las crónicas cristianas con el nombre de Soysemeles.” La arabista funda su opinión en una fuente tardía, la Historia de la casa de Granada, escrita en el siglo XVI. El nombre realmente viene de la Crónica de Alfonso X, donde en un lugar el escritor habla sobre la familia Soysemela. De modo que únicamente podemos afirmar que hay una primera fuente que la llama Soysemela y, luego, otra más tardía que se basa en ella. Véanse: GONZÁLEZ JIMÉNEZ, Manuel, Crónica de Alfonso X: Según el Ms. II/2777 de la Biblioteca del Palacio real (Madrid), Murcia 1999, 6; y BALLESTEROS BERETTA, Antonio, "Itinerario de Alfonso X, rey de Castilla (1265-1267)", en Boletín de la Real Academia de Historia 109 (julio-septiembre 1936) 393-394.

${ }^{14}$ Se trata de una parte ausente en todas las ediciones sobre las terceras taifas y los reinados de los primeros cuatro emires nazaríes. ŽENKA, Josef, "Las terceras taifas en un nuevo manuscrito del A 'māl/I I'māl al-a'lām de Ibn al-Jațīb”, en Manuscritos árabes en España y Marruecos: ¿espacios compartidos?, Mostafa Ammadi, Francisco Vidal Castro y María Jesús Viguera Molíns (eds.), Casablanca 2013, 181-190.

${ }^{15}$ MS 205 de la biblioteca de la Fundación del rey 'Abd al-`Azīz en Casablanca, 189, línea 6 اشقيلولة اشقيليولة - اشيونة (Išqaylūla), 189, línea 7 (Išliyūla).

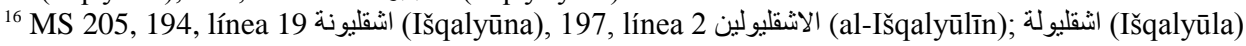
190, línea 22, 191, línea 5, 194 líneas 2 y 20, 196 línea 7.

${ }^{17}$ LÉVI-PROVENÇAL, Évariste, Inscriptions arabes d'Espagne, Leyden - Paris 1931, 139-142; plancha XXXIV. 
Escorial que contiene la obra de al-Bunnāhī al-Iklīl fì taf̣̣̂ll al-najīl. ${ }^{18}$ Después de un minucioso examen de la reproducción de la inscripción en la lápida funeraria, que Lévi-Provençal transcribió como Ašqīlūla, encontré para mi asombro la forma اسفلوله, que es la misma que aparece en el manuscrito de $A$ 'māl al-a 'lām. Una nueva sorpresa me iba a ser deparada después del análisis del nombre en los escritos de alBunnāhī, donde no sólo se encuentra la misma forma, sino que además está vocalizada como Išqalyūla o $\mathrm{A} / \mathrm{I} / \mathrm{Ušq}$ lyūla. Dado que el manuscrito fue revisado y corregido por el propio al-Bunnāhī, me pareció lógica la elección de la variante Išqalyūla y escribí una breve nota al respecto. ${ }^{19}$ Aquí intentaré demostrar que la forma Išqalyūla es realmente el nombre árabe correcto de esta familia y que se trata de la transcripción literal de la palabra escallola/escalhola al árabe clásico. La forma Ašquilūla no es sino un neologismo.

Ya Rubiera señaló con detalle la cuestión de la transcripción en árabe de ese nombre en su artículo sobre esta familia: "La grafía árabe اشثقلولة se ha leído Ašqīlūla, dada la ambigüedad que siempre ofrece la escritura árabe cuando intenta reproducir una forma que le es ajena, sin embargo, su lectura correcta es fácil, ya que se encuentra en fuentes cristianas contemporáneas a la existencia de la familia de este nombre." Su análisis lo finaliza advirtiendo que "habría que leer la grafía árabe como Išqaylūla, si se quieren conservar de alguna forma las vocales árabes clásicas que de ningún modo sonarían así.” ${ }^{20}$ Rubiera examinó el nombre de la familia basándose en fuentes árabes ya editadas y accesibles, sobre todo I $h \bar{a} t \underline{t} a$ y $A ' m \bar{a} l$ al-a lām de Ibn al-Jațīb, y hasta ahora nadie ha refutado su tesis sobre el significado del nombre de la familia Išqalyūla ni sobre la transcripción que propone. En la literatura, sin embargo, se ha seguido utilizando la forma Ašqīlūla, ignorando, como decimos, el artículo de Rubiera. Es probable que Lévi-Provençal reforzase tal tendencia con su transcripción como Ašqīlūla de la lápida funeraria de Jaén, y lo mismo cabe decir de Allouche a propósito de su traducción de Ibn al-Jațīb. ${ }^{21}$ Sin embargo, después de analizar esta inscripción y varios manuscritos, la hipótesis de

${ }^{18}$ Este manuscrito está en la historia mal llamado Nuzhat al-bașā'ir wa-l-abṣār, puesto que su nombre verdadero es al-Iklīl fì taf̣̣̂ll al-najīl. El editor saudí de esta obra lo explica en las páginas 5153 de su tesina, donde habla sobre la verdadera obra Nuzhat al-bașā'ir wa-l-abșār, y en las páginas 73-75, en las cuales explica el porqué del nombre de al-Iklīl fì taf̣̣̂l al-najīl según el texto del manus-

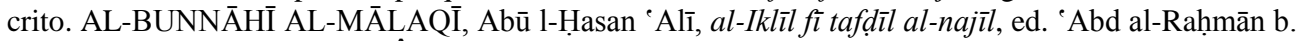
Muhammad Haybāwī, S.1., al-Ŷ̄āmi a al-islāmīya li-l mamlaka al-'arabīya al-sa ū ūìya, 1426-1427. Su edición se puede consultar libremente aquí:

http://scholars.iu.edu.sa/index.php/scholarsAr/issue/view/275 [Último acceso el 17 de marzo de 2014]

${ }^{19}$ ŽENKA, Josef, "Las terceras taifas en un nuevo manuscrito del A 'māl/I' māl al-a' lām de Ibn alJațīb”, en Manuscritos árabes en España y Marruecos: ¿espacios compartidos?, Mostafa Ammadi, Francisco Vidal Castro y María Jesús Viguera Molíns (eds.), Casablanca 2013, 183, n. 10.

${ }^{20}$ RUBIERA DE EPALZA, María Jesús, "Los Banū Escallola, la dinastía granadina que no fue”, en Andalucía Islámica 2 (1981-82) 85.

${ }^{21}$ ALLOUCHE, I. S., "La révolte des Banū Ašḳīlūla contre le sultan Naṣrīte Muhammad II d'aprés le kitāb a māl al-ā'lām d'Ibn al-Hูațīb", en Hésperis XXV (1938) 1-11. 
Rubiera de que la forma Ašqīlūla es un neologismo, y por tanto la transcripción correcta debería ser Išqaylūla, acaba por verificarse con un pequeño matiz añadido. Originalmente la forma no se escribía Išqaylūla (اشقيلولة), sino Išqalyūla (اشقليولة).

Para confirmar que se trata de una transcripción de las palabras escallola/escalhola nos valemos de nuevas fuentes, que es precisamente lo que sugirió hace muchos años García Gómez. ${ }^{22}$ En primer lugar cabe decir que la tesis de Rubiera tenía una pequeña imperfección. La palabra escallola contiene $>l l<$ que no es otra cosa que representación del sonido $/ \lambda$ / (lleísmo). La lengua árabe clásica, que carece del sonido $/ \lambda /$ - representado en hispanorromance como $>$ ll $<$ (escallola) y en gallego-portugués como como $>\mathrm{lh}<$ (escalhola)—, no transcribe este mediante $>$ yl $<$ (es decir, (2). ciris y como ejemplo nos pueden servir, además del nombre Išqalyūla, algunos topónimos que entraron en castellano con pronunciación en forma de yeísmo, a pesar de que el árabe clásico los transcribiese como $>\mathrm{ly}<-$ por ejemplo Illora (Ilyūra), Crevillente (Qirbilyān) etc. ${ }^{24}$ Amado Alonso describió este fenómeno entre los moriscos basándose en obras gramaticales. Entre los gramáticos de la época encontró constancia de que, cuando todavía había población morisca en la Península Ibérica, ésta no podía pronunciar el propio sonido $/ \lambda /$, articulándolo finalmente como /li/. Y así es exactamente como está escrito el nombre en la inscripción funeraria de 'Alī Ibn Išqalyūla. La no existencia de $>\mathrm{yl}<$, así como esta dificultad de los moriscos a comienzos del siglo XVI para pronunciar el sonido $/ \lambda /$, refuerzan lo que dicen las fuentes escritas. Sin embargo, en el momento de escribir su estudio, Rubiera no tenía a mano -o al menos no parece saber nada de ella- la fuente que confirmaba esta opción correcta con $>\mathrm{ly}<$ (لي). Por lo tanto, no tenía motivo alguno para pensar que algo podría ser incorrecto o estar escrito de manera diferente.

Optó Rubiera así por una variante, Išqaylūla, conforme a la transcripción del nombre en las fuentes árabes editadas que, en esencia, contradecía parcialmente su tesis, ya que la forma en sí es una transcripción ajena al árabe. La versión correcta, sin embargo, está en los manuscritos. Y no en uno solo, dado que la familia aparece en muchas crónicas y en otros documentos.

Como base de este análisis deberíamos tomar la inscripción funeraria conservada de al-ra' ’̄s Abū 1-Ḥasan Ibn 'Abd Allāh Ibn Išqalyūla al-Tuŷībī, nieto del

\footnotetext{
${ }^{22}$ Emilio García Gómez presentó su opinión en el prólogo al libro sobre Ibn al-Ŷayyāb: "La autora de este libro ha formulado una ingeniosísima hipótesis sobre el origen del nombre de los Banū Ašqūlūla (AA XXXI, 1966). He tenido que estudiar la cuestión y mi opinión - sin certeza absoluta - es otra, no para ser expuesta aquí. La discrepancia surge de que el texto de la Iháta no está en prosa rimada y acaso por eso, mal fraseado, se halla escrito en un descuido y es ambiguo. Hay que compulsar otras fuentes.” RUBIERA MATA, María Jesús, Ibn al-Ŷayyāb: El otro poeta de la Alhambra, Granada 1994, 11.

${ }^{23}$ Las formas castellana y portuguesa las utilizé por estar documentadas en dichas lenguas, tanto en fuentes contemporáneas como en otras posteriores.

${ }^{24}$ Es muy probable que en su momento no se pronunciaran con yeísmo.
} 
primer emir granadino fallecido el 3 de mayo de 661 (1263). ${ }^{25}$ Junto a la lápida funeraria, elaborada durante la existencia de esta familia, me serví para el análisis de una serie de manuscritos de obras granadinas, entre ellos algunos de los redactados en Granada cuando la memoria y el legado de la familia Išqalyūla todavía estaban vivos en al-Andalus.

Respecto a los manuscritos, conviene recordar que la biblioteca del Monasterio de San Lorenzo de El Escorial guarda una cantidad de ellos lo suficientemente amplia como para reforzar la tesis que aquí defiendo, mostrándonos la evolución de la transcripción del nombre en lengua arábiga. A estos añadí otros dos, procedentes de diferentes bibliotecas, que nos podrán aclarar la existencia y evolución de las dos variantes. Los que mencionamos a continuación, a menos que se indique lo contrario, proceden todos de El Escorial:

1. Inscripción funeraria depositada actualmente en el Museo Arqueológico de Córdoba. Pertenece al nieto del primer emir nazarí a través de su hija. ${ }^{26}$

2. Manuscrito número 1776 de la obra de Ibn al-Jațīb al-Lamha al-badrīya. ${ }^{27}$ Esta crónica está escrita en bella letra andalusí, del mismo tipo que la empleada en el manuscrito 1653 de al-Bunnāhī. Ambos tienen una caligrafía muy similar. La crónica se halla completamente vocalizada, casi sin errores y sin lagunas. No contiene la fecha de su redacción, pero en mi opinión fue copiada del original poco después de la redacción de éste. Esto es, después de ramaḍān 765 (2 de junio 1364-1 de julio de 1364), cuando según el colofón fue terminada la segunda obra de este códice "al-manżūm wa-l-mašrūh de Raqm al-hulal fì naẓm al-duwal”. También creo que antes de la última encuadernación el orden de las obras en el códice fue contrario: Lamha iba primero y Raqm al-ḥulal con šarḥ después. ${ }^{28}$ Por eso, y debido a su fidelidad

${ }^{25}$ Aquí es importante advertir de que se trataba de un descendiente de la hija de Muhammad I, fruto de su primer matrimonio/concubinato, y no del segundo, como opina Boloix Gallardo. Según la inscripción funeraria Abū l-Ḥasan Išqalyūla nació el día 8 de ša bān 634 (6 de abril de 1237). Si nos valemos de un cálculo sencillo nos sale la cuenta, tomando en consideración la edad mínima teórica para el embarazo, pues su madre debió de nacer antes que Faraŷ, el hijo mayor que Muhammad I tuvo con su otra mujer, su prima. BOLOIX GALLARDO, Bárbara, Las sultanas de la Alhambra: Las grandes desconocidas del Reino Nazarí de Granada (siglos XIII-XV), Granada 2013, 50-51.

${ }^{26}$ Según Boloix, "actualmente se halla custodiada en el museo arqueológico de Córdoba bajo la referencia «N.R. 512».” Véase BOLOIX GALLARDO, Bárbara, Muhammad I. y el nacimiento del alAndalus nazarí (1232-1273): Primera estructura del reino de Granada, Granada 2007, 84-89. Tesis doctoral inédita. La autora nos aporta las fotografías actuales de la lápida funeraria. Tal imagen, al igual que su ubicación, la menciona también Vidal Castro. Véase VIDAL CASTRO, Francisco, "El papel de Jaén en la creación del Reino Nazarí de Granada, El último al-Andalus”, en Jaén época de los nazaríes (al-Andalus, s. XIII-XV): Estudios de historia y patrimonio cultural islámico y cristiano, Francisco Vidal Castro (ed.), Alcalá la Real 2010, 93.

${ }^{27}$ MS 1776, folio 91r, línea 6.

${ }^{28}$ Lo indica la información contenida en el folio 72r. 
al texto original y la exactitud de sus antropónimos y topónimos, se trata de un manuscrito importantísimo. ${ }^{29}$

3. Manuscrito número 1653 de la obra de al-Bunnāhī al-Iklīl fì taf̣̣̂ll al-najūl Fue compuesto en 1379, al comienzo de raŷab de 781, y está casi por completo vocalizado. ${ }^{30}$ En el penúltimo folio, el 109v, figura una nota autógrafa de al-Bunnāhī indicando que se trata de una copia del original que fue revisada y corregida por él. ${ }^{31}$

4. Manuscrito número 1674 de la obra de Ibn al-Jațīb al-Iḥāta fí ajbār Ġarnāta Es uno de los dos ejemplares conservados de la versión original de la Ihạtạ de Ibn al-Jațīb y no sólo de mujtașar. Este manuscrito está fechado 15 de ramaḍān de 806 (27 de marzo de 1404) y es mucho más preciso que, por ejemplo, el manuscrito 1673. Se encuentra en un estado de deterioro considerable. ${ }^{32}$

5. Manuscrito número 1673 de la parte de la obra al-Ihạța fì ajbār Ġarnāta en forma de mujtașar de Ibn al-Jațīb.

Esta versión de mujtaṣar fue redactada, según 'Abd Allāh 'Inān, por Aḥmad al-Baqqānī. ${ }^{33}$ Se trata de un documento fechado a principios del mes de rabī' al-awwal de 895 (febrero de 1490). ${ }^{34}$

6. Manuscrito número 1755 del segundo volumen de la obra de Ibn al-Jațīb Nufā dat al-ŷirāa fì 'ulālat al-i 'tirāb.

Aunque no consta fecha, lo más probable es que se trate de una copia redactada en Granada a finales del siglo XIV o principios del siglo XV..$^{35}$

${ }^{29}$ Como ejemplo puede servir el nombre del primer wazīr de Ismāēill I que se transcribe en la literatura como Nașīr, Nāṣir o Nușayr. Según este manuscrito, se trata de Nușayr. Respecto al códice 1776, desde los tiempos de Lévi-Provençal se dice que contiene tres obras. Sin embargo, esta información no es del todo exacta. El códice original contenía solamente las dos obras de Ibn al-Jațīb. La tercera según Lévi-Provençal, Trois pages sur les merveilles d' al-Andalus sans titre ni nom de autor, que está también en el folio $3 r$ - es realmente una larga glosa interpuesta entre las dos susodichas. Se debe a una mano diferente y su escritura es más tardía que la del original.

${ }^{30}$ El editor saudí siempre escribe انشقليولة (sin vocalizar) y no menciona la existencia de otras varian-

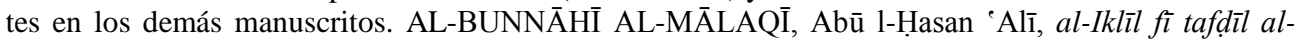
najīl, ed. 'Abd al-Raḥmān b. Muhammad Haybāwī, s.l. 1426-1427, 240 y 242.

31 "Revisé este libro copiado del original que lo precedía, y que yo había titulado al-Iklīl fì tafḍ̂l al-najīl, con Maqāma, y lo corregí todo.” MS 1653, f. 109v.

انشقليوله El nombre está en las biografías de 'Abd Allāh Ibn Ibrāhīm y su sobrino. Bajo la forma (Išqalyūla, sin vocalizar) lo encontramos en la página 48, línea 10, en la página 49, línea 11, y en la página 51 en líneas 8 y 13. En un caso -página 49, línea 1- aparece, debajo de, alif kasra. En la página 51, línea 8, el copista pone solamente un punto debajo de $y \bar{a}{ }^{\prime}$ (اسقلبوله).

${ }^{33}$ IBN AL-JAṬ̂̄B, Lisān al-Dīn, Rayḥāna al-kuttāb wa nuŷ'at al-muntāb, ed. Muhammad 'Abd Allāh `Inān, al-Qāhira 1980, vol. I, 7.

${ }^{34}$ Respecto a este manuscrito veáse: SIYĀR, Abdel-ilāh, "Al-Iḥata fî tarīj Garnāta: evaluación de un manuscrito", en Actas del 1er coloquio internacinal sobre Ibn al-Jatib (Loja, 28 y 29 de octubre de 2005), Juan Alonso Sánchez Martínez, Mustafa Akalay Nasser (coords.), Loja s.f., 119-130. 
7. Manuscrito número 205 de la parte del segundo volumen de la obra de Ibn al-Jațīb $A$ 'māl al-a 'lām, conservado en la Biblioteca de la fundación del rey 'Abd al-Azìz en Casablanca.

No tiene fecha, pero es más reciente que el anterior y creo que se remonta al siglo XV o XVI. ${ }^{36}$

8. Manuscrito número 7257 de la Biblioteca Nacional de Francia de la parte de la obra de Ibn al-Jațīb al-Ihạtạ fì ajbār Ġarnāta en forma de mujtașar Es una copia tardía del siglo XVII realizada en el norte de África. Se trata de una versión de mujtașar idéntica a aquélla en la que se basó 'Abd alSalām Šaqqūr en el apéndice a los nuevos textos de al-Ihạța. ${ }^{37}$ Constituye, pues, un resumen diferente al de la selección de Aḥmad al-Baqqānī.

De estas ocho fuentes, las primeras cuatro contienen la forma انقليولة, que para más señas está completamente vocalizada en los manuscritos 1776 y 1653 (fuentes 2 y 3). Los dos siguientes optan por la forma اشقيلولة, y de ellos el manuscrito número 1755 lleva fatha en šin y sukūn en qăf. De los dos últimos (fuentes 7 y 8 ) ha de decirse que la forma se respeta (اشقليولة en 7 y 8), aunque en algunos lugares los escribanos se equivocaron y pusieron transcripciones diferentes. Los seis primeros $^{38}$ son constantes en la transcripción y mantienen una de las dos formas mencionadas, aunque ninguno da señales de la vocalización de Ašqīlūla. Como forma de referencia hemos de tomar, en mi opinión, la escritura de la inscripción de la lápida funeraria conservada, pues es la única de la que podemos estar seguros que surgió en tiempos de la familia Išqalyūla. La reproducción de esta lápida la publicó Lévi-Provençal, y en ella (como puede verse en la imagen ampliada Figuras 01-02) es claramente visible que lām precede a $y \bar{a}$ '. La pregunta, por tanto, es dónde vio el editor la forma transcrita en el libro. Por mi parte debo admitir que fracasé, incluso después de examinarla a fondo con mis propios ojos, valiéndome unas veces de una lupa y otras de numerosos retoques con Photoshop, a la hora de ver una forma diferente a اسفلوله (Išqalyūla). ${ }^{39}$ En la inscripción de la lápida no es visible esa fatḥa en

${ }^{35} \mathrm{El}$ editor de este manuscrito dice: "Las fuentes difieren acerca de la escritura de este nombre. Unas veces aparece con kasra en alif y otras con fatḥa en él. En este caso aparece sin alif. " IBN ALJAṬ̂̄B, Lisān al-Dīn, Nufāọat al-ŷirāa fì 'ulālat al-i 'tirāb, eds. Ahmmad Mujtār al-'Abbādī, 'Abd al'Azīz al-Ahwānī, al-Qāhira s. f., 331, n. 7.

${ }^{36}$ Para la descripción del manuscrito véase ŽENKA, Josef, "Las terceras taifas en un nuevo manuscrito del A'māl/I'māl al-a' lām de Ibn al-Jațīb", en Manuscritos árabes en España y Marruecos: ¿espacios compartidos?, Mostafa Ammadi, Francisco Vidal Castro y María Jesús Viguera Molíns (eds.), Casablanca 2013, 183-4.

${ }^{37}$ Las biografías editadas en el capítulo “al-Mulhaqa”. IBN AL-JAṬĪB, Lisān al-Dīn, al-Ihāṭa fì ajbār Ġarnātạ: Nușūṣ ŷadīda lam tunšar, ed. ‘Abd al-Salām Šaqqūr, Tiṭ̂ān 1988, 239-271.

${ }^{38}$ Con excepción de un lugar en MS 1674. Véase nota 32.

${ }^{39}$ Se plantea aquí cuestión de si Lévi-Provençal no transcribió más bien la forma que en realidad quería ver. Es necesario recordar que el trabajo del arabista francés no fue siempre impecable, para 
alif transcrita por Lévi-Provençal, por lo que sólo podemos concluir una cosa: en el momento de la muerte de Abū l-Ḥasan Ibn Išqalyūla, su familia había consentido elaborar la inscripción en esta forma libre de puntos y signos diacríticos (اسفلوله).

No se han conservado otras lápidas funerarias de la familia en la Península Ibérica, pero sí la transcripción de la de 'Abd Allāh b. Ibrāhīm b. 'Alī Ibn Muḥammad al-Tuŷî̉ī, primo de Abū 1-Ḥasan. Sabemos que Ibn al-Jațīb visitó la tumba del famosísimo al-ra’̄is y apuntó la inscripción de la lápida para incluirla después en la semblanza biográfica que le hace en Ihătạ. Aparece en cada uno de los tres manuscritos de Ihạța (Mujtașar) que he podido consultar. En el 1674 (fuente número 4) y en 1673 se halla también la biografía de su tío, el padre de Abū 1-Ḥasan. En el primero de ellos está en todos los lugares, incluyendo la transcripción de la lápida funeraria, bajo la forma اشقليولة. Sólo en uno se halla la escritura Išqalyūla con kasra debajo de alif (p. 49, línea 1). Por lo tanto, en uno de los dos ${ }^{40}$ únicos manuscritos conservados de la Ihâța original (fuente número 4), figura la misma forma del nombre que aparece en la lápida funeraria. Los otros dos manuscritos de Ihạta mujtașares considerablemente más tardíos que el manuscrito 1674- recogen en las semblanzas de los miembros de la familia la forma اشقيلولة sin vocalización. Es una lástima que no se hayan conservado los textos de las otras lápidas funerarias, máxime si tenemos en cuenta que, según cierta misión científica francesa realizada en los primeros años del siglo XX, por entonces aún quedaban en Alcazarquivir algunas tumbas originales de los miembros de la familia, si bien ya por entonces se encontraban en estado ruinoso. ${ }^{41}$

Otra fuente granadina de la época la constituye un manuscrito de la obra de Ibn al-Jaṭīb al-Lamha al-badrīya (Fuente número 2). Aquí la palabra اشثليولة aparece una vez, concretamente en el capítulo dedicado a los acontecimientos acaecidos durante el reinado de Muhammad II. ${ }^{42}$ El nombre está casi completamente vocalizado como Išqlyūla (sic). La misma forma, pero sin vocalización, la utilizó en su edición de

lo que bastaría mencionar la primera edición de la crónica $A$ 'māl al-a 'lām de Ibn al-Jațīb o la edición de al-Bunnāhī.

${ }^{40}$ El segundo es un manuscrito depositado en la biblioteca Ruwāq al-Maḡāriba bi-l-Azhar en Cairo. Consta de 170 folios por los cuales desfilan el resto de la I $h \bar{a} t \underline{t a}$ original enviada a Egipto por Ibn alJațīb y contiene las glosas marginales autógrafas de al-Maqqarī. IBN AL-JAṬ̂̄B, Lisān al-Dīn, alIhātạ fì ajbār Ġarnātạ, ed. Būzayyānī al-Darrāŷī, al-Ŷazā'ir, s.f., vol I, 104. El tercer fragmento de la I hạta original representan varios folios conservados en la biblioteca Qarawiyīn en Fez. Veáse IBN AL-JAṬ̂̄B, Lisān al-Dīn, al-Ihāạta fì ajbār Ġarnātạ, ed. Muḥammad 'Abd Allāh `Inān, al-Qāhira 2001, vol. I, 16.

${ }^{41}$ Según los Archives Marocaines, a comienzos del siglo XX permanecían allí las tumbas de Muhammad b. Išqalyūla (Mouḥammad ben Achqîloûla) y 'Alī Šarīf b. Išqalyūla (Ali Cherif ben Achqîloûla), descendientes de ar-ra'īs 'Abd Allāh. Sin embargo los autores no revelan si todavía existían las tumbas con algunas lápidas funerarias originales. Véase MICHAUX-BELLAIRE, E. y SALMON, G., "El-Qçar El-Kebir: Une ville de province au Maroc septentrional”, en Archives Marocaines II, 2 (1904) 177-178.

${ }^{42}$ Ms. 1776, folio 91r, línea 6. 
dicha obra Muhibb al-Dīn al-Jațīb, ${ }^{43}$ aunque este hecho le pasó desapercibido al traductor Casciaro ${ }^{44}$, así como al nuevo editor Muhammad Mas'ūd Ŷibrān. ${ }^{45}$ Sin embargo, ambos dicen haber consultado el manuscrito y haberle cotejado durante su trabajo. ${ }^{46}$ De la misma forma con vocalización se vale también al-Bunnāhī (fuente número 3), contemporáneo de Ibn al-Jațīb. En este caso aparece dos veces, primero completamente vocalizada como Išqalyūla (37v) y, luego, parcialmente (38v), llevando sukūn en šinn. Este manuscrito es incluso más valioso, ya que fue revisado y corregido por el propio al-Bunnāhī. Se comprueba así que la forma Išqalyūla estaba, por lo tanto, difundida en la segunda mitad del siglo XIV, y también que se conocía en la Granada Nazarí, hasta el punto de poder decir que al-Bunnāhī tenía una clara idea sobre su pronunciación. Asimismo se puede sobreentender que, al igual que Ibn al-Jațīb, pudo consultar libros hoy no conservados o ver en persona tumbas y lápidas funerarias de algunos miembros de esta familia en Granada o en el Norte de África. Los dos amigos, más tarde enemigos, debían por tanto de conocer la forma correcta de transcripción de la palabra, que no es otra que la que encontramos en la lápida funeraria. Incluso es de recibo advertir que Ibn al-Jațīb, como ya justificase Rubiera, conocía su significado, ${ }^{47}$ lo cual no es un hecho irrelevante: si fue así, eso significa que la pudo correcta y fielmente transcribir, pues no puede ponerse en duda su vasto conocimiento de lenguas. Gracias a su rigor lingüístico y a su excelente memoria, no hay razón alguna para no confiar en la fiabilidad de su proceder.

Los tres manuscritos mencionados (1776, 1653 y 1674 - Figuras 3-7) datan indiscutiblemente de un tiempo no muy lejano a la redacción de las obras originales y suponen, pues, una clara confirmación de que en la segunda mitad del siglo XIV el nombre de esta familia se escribía de la misma manera que en la lápida funeraria (اشقليولة), con puntos). No obstante, también son, junto con ella, los únicos que se valen exclusivamente de la forma Išqalyūla. Quizá la clave de este problema haya que buscarla en el uso que hacen de la palabra los manuscritos 'Amāl al-A 'lām de la biblioteca de la fundación del rey 'Abd al-'Azīz en Casablanca y la Ihăta de la Biblioteca Nacional de Francia. Puesto que el primero de ellos contiene por lo menos cuatro variantes, cabe con razón presumir que el copista no tenía ni idea de lo que significaba la palabra ni de cómo escribirla correctamente (FIGURAS 8 y 9). Era para él un típico problema de transcripción de un nombre propio de origen no árabe

${ }^{43}$ IBN AL-JAṬ̄̄B, Lisān al-Dīn, al-Lamha al-badrīya fì al-dawla al-nașrīya, ed. Muhibb al-Dīn al-Jatīib, al-Qāhira 1348[1929-1930], 44.

${ }^{44}$ CASCIARO, José María, Historia de los reyes de la Alhambra: El resplandor de la luna llena, Granada1998, 91.

${ }^{45}$ IBN AL-JAṬīB, Lisān al-Dīn, al-Lamha al-badrīya fì al-dawla al-nașrīya, ed. Muhammad Mas'ū Ŷ̀ibrān, Bayrūt 2009, 82.

${ }^{46}$ En realidad Casciaro utilizó la forma Išqiliwla en su artículo sobre el visirato en el emirato Nazarí. Véase CASCIARO, José María, "El Visirato en el Reino Nazarí de Granada”, en Anuario de Historia del derecho Español 18 (1947) 242.

${ }^{47}$ RUBIERA DE EPALZA, María Jesús, "Los Banū Escallola, la dinastía granadina que no fue", en Andalucía Islámica 2 (1981-82) 86-87. 
que le resultaba desconocido. El mujtașar de Ithāta de la Biblioteca Nacional de Francia confirmaría esta hipótesis: su copista trata de mantener la forma Išqaylūla

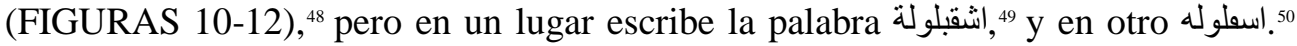
Creo que en los otros manuscritos, incluyendo la más usada copia de mujtașar de Ihâta de al-Ahmad Baqqānī nos encontramos con el mismo problema. Los escribanos copiaron estas obras cientos de años después de la desaparición de la familia Išqalyūla de la historia de la Granada Nazarí y, por lo tanto, a diferencia de los autores de dichas obras, no contaban con ninguna noción sólida que les permitiese salvaguardar la forma correcta. En el caso de la copia de al-Baqqānī también se podría muy bien recordar que contiene un gran número de errores. ${ }^{51} \mathrm{~A}$ este problema con el manuscrito escurialense en el proceso de la identificación de la familia Išqalyūla remitió en su día García Gómez. Asimismo, existe en los mujtaşares una gran confusión respecto a las biografías de la familia Išqaylūla. Lo demuestra claramente el manuscrito de la Biblioteca Nacional de Francia. Las dos biografías, de sobrino y tío Išqalyūla respectivamente, se nos presentan unidas en una sola semblanza bajo el nombre del primero sin mencionar, ni tan siquiera señalar, que una parte del texto original se refiere también al otro personaje. ${ }^{52}$

También en copias tardías se conservan otras obras que contienen el nombre de Išqalyūla. Así, dos ejemplares de Faṣl al-Jițāb de Ibn Jaț̣āb pueden servir a su vez de ejemplo de confusión entre los escribanos. Mientras en alguno se lee la forma اشقيلولة en otro no encontraremos más que un lugar en blanco. ${ }^{53}$ Cada editor lo transcribe de forma diferente: 'Azzāwī como اشقيلولة, sin vocalización, ${ }^{54}$ y el-Ghailani como Ašqilūla, completamente vocalizado. ${ }^{55}$ Más: de otras obras granadinas, que también se conservan sólo en copias tardías, cabe justamente presumir que los escribanos se aproximaron a la palabra de igual manera y con similares confusiones.

${ }^{48}$ MS 7257, dos veces en folio 116v - en la biografía Ya ${ }^{\circ} q u \bar{b}$ Ibn 'Abd al-Haqq y dos veces en folio 56v en la biografía de al-ra' '̌s 'Abd Allāh b. Ibrāhīm Išqalyūla.

${ }^{49}$ En biografía de al-ra '̄̌s 'Abd Allāh, MS 7257, folio 56v, línea 4.

${ }^{50}$ En la biografía de al-ra'īs Abū Sa īid Faraŷ al mencionar al-ra'īs 'Abd Allāh b. Išqalyūla. MS 7257, folio 106r, línea 15. En este punto cabe preguntarse si el copista barruntó que se trataba de un miembro de esta familia.

${ }^{51}$ Hasta ahora no se ha publicado un estudio detallado sobre las relaciones entre las copias manuscritas preservadas de I $h \bar{a} t a$, que muy bien podría explicar la evolución de las versiones abreviadas, así como su mutua dependencia.

${ }^{52}$ Después de escribir este estudio encontré el mismo problema en dos manuscritos de mujtașares de al-Ihāta pertenecientes a la biblioteca de la Real Academia de la Historia. A pesar de la afirmación contraria de 'Inān respecto a la copia de Gayangos, los dos manuscritos son tardíos y proceden de la copia Tunecina de al-Ihâta .

${ }^{53}$ Lo que en sí mismo remite a cierto problema de inteligibilidad de la palabra por parte del copista.

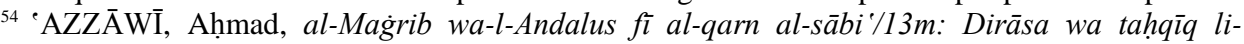
dīwānīyāt kitāb Faṣl al-Jiṭāb fì tarsīl Abī Bakr Ibn Jațțāb, al-Ribāt 2008, 97 y 98. El segundo registro en la página 98 es adición del editor.

${ }^{55}$ EL-GHAILANI, Hassan, Edición y estudio "Fașl al-Jițāb” de Abū Bakr Ibn Jațtāa al-Mursī, Madrid 1994, tesis doctoral inédita, 112. 
Por ejemplo, el manuscrito de Tuhfat al-mugtarib, que data del siglo XV, no fue trasladado, según Fernando de la Granja, su editor, de manera especialmente cuidada o elegante. ${ }^{56}$ Con respecto a esto, una vez más surge la pregunta de hasta qué punto el copista podría estar familiarizado con este nombre. El apelativo de la familia está también en otra obra granadina Dikr bilād al-Andalus, de autor anónimo, ${ }^{57}$ en al-Marqaba al-Bunnāhī, en algunas obras magrebíes ${ }^{58}$ e incluso en una crónica oriental. Así, Baybarṣ al-Manșūrī la menciona una vez en una composición fundamental y plagada de datos sobre Maġrib y al-Andalus, Zubdat al-fikra fi ta'rijj alhiŷra. Su editor, Donald Richards, transcribió el nombre de la familia como alŠaqaylūla, tomando nota de que uno de los manuscritos no llevaba esta vocalización. ${ }^{59}$ Cuando menos, esto prueba que en Oriente tenía el cronista conciencia de que el nombre de esta familia era de pronunciación difícil y completamente ajena a su oído egipcio.

Pero no solamente a un autor egipcio le sonaría extraño, pues también los autores andalusíes granadinos dan muestras de vacilación. Ello explica por qué los autores o copistas andaluces de los manuscritos sentían la necesidad de poner la vocalización completa o parcial del nombre de la familia. Por lo tanto, ahora somos capaces no solamente de transliterar el nombre, sino también de transcribirlo para demostrar que la teoría de Rubiera está bien documentada en las fuentes árabes. La vocalización en al-Bunnāhī (manuscrito 1653) e Ibn al-Jațīb (ms. 1775) bajo la forma Išqalyūla resulta absolutamente fiel a la transcripción de las palabras escallola/escalhola) en la lengua árabe clásica. Ninguno de los manuscritos, ni siquiera en el más mínimo indicio, confirma la vocalización hasta ahora utilizada que, por lo demás, después del cambio de lām y yā' pierde cualquier tipo de apoyo. En total, tres manuscritos $(1776,1653,1674)$ mencionan al menos en un lugar que alif

${ }^{56}$ AL-QAŠTĀL̄̄̄, Aḥmad, Milagros de Abū Marwān al-Yuhānisī, editados, con prólogo, notas e índices por Fernando de la Granja, Madrid 1974, 7 del texto árabe y 13 del español. De la Granja dice: “El manuscrito de la Tuhfa no está fechado (siglo XV) - es de letra magrebí, nada elegante y muy descuidada, carece a menudo puntos diacríticos con sólo unas pocas palabras entera o parcialmente vocalizadas.” La traductora de la obra tiene la misma opinión: "De su caracterización, puedo afirmar que está escrito en su totalidad en un tipo de letra andalusí-magrebí muy descuidada pero legible, según he podido apreciar directamente en la copia del manuscrito de que dispongo. Por lo general, la obra presenta escasos signos de puntuación, ya que no suelen ser reflejados los puntos diacríticos de algunas letras, lo que dificulta muchas veces la identificación de las palabras; la vocalización es, asimismo, exigua.” BOLOIX GALLARDO, Bárbara, Prodigios del maestro sufi Abū Marwān al-Yuhānisī de Almería: Estudio crítico y traducción de la Tuhfat al-Muġtarib de Aḥmad al-Qaštālī, Madrid 2010, 22.

${ }^{57}$ Una descripción anónima de al-Andalus, Editada y traducida, con introducción, notas e índices por Luis Molina, Madrid 1983, Tomo I: Edición, 5.

${ }^{58}$ En todas las obras se escribe como اشققيلولة. La familia Išqalyūla se halla en las crónicas de Ibn 'Id̄ārī al-Marrākušī, Ibn Jaldūn, Ibn Abī Zar' y en la obra anónima al-Dajīra al-sanīya. El editor de la antigua edición de 1921, Ben Cheneb, vocaliza esta palabra como Išqaylūla. Ad-Dahîrat As-Saniyya (Le trésor magnifique): Chronique anonyme des mérinides, ed. Mohammed Ben Cheneb, Algiers 1921, 64.

${ }^{59}$ BAYBARȘ AL-MANȘŪRĪ, Rukn al-Dīn, Zubdat al-fikra fì ta'rīj al-hîyra, ed. Donald S. Richards, Bayrūt 1998, 135. De aquí toma también la información el cronista al-`Aynī. 
lleva kasra. La forma de Išqalyūla se apoya también en Nufāḍa y en el dato mencionado en la crónica de Baybars. Asimismo, 'Abd Allāh 'Inān debía de ser consciente de ello, o al menos haber encontrado vocalización en otros manuscritos de mujtașar de Ihạta. Solamente de este modo se puede explicar por qué el nombre se vocaliza sistemáticamente como Išqaylūla. ${ }^{60} \mathrm{El}$ hecho de que utilizase en su edición también el manuscrito 1674 puede ser seriamente puesto en duda. Si ese fuera el caso, Šaqqūr no tendría ningún trabajo. Por todo lo mencionado podemos, pues, considerar Išqalyūla como el único nombre documentado en las fuentes contemporáneas o cercanas a esta importante familia urgabonense. Se trata, insistimos, del fiel registro árabe de la palabra escallola/escalhola llevado a cabo con las típicas modificaciones derivadas de la transcripción.

\section{CONCLUSIONES}

La familia Išqalyūla ocupa un lugar importantísimo en la historia de la Granada Nazarí. Por esta razón, es necesario abandonar una transcripción incorrecta de su nombre y, conforme la tesis aquí sostenida, empezar a denominarla como realmente se llamaba: Išqalyūla (Escallola/Escalhola). El significado de este nombre, según ya demostró de manera muy persuasiva la llorada Rubiera Mata, así como su transcripción, no se han visto refutados desde la aparición de su artículo sobre Banū Hubayba/Escallola ${ }^{61}$ por ninguna otra hipótesis. Muy al contrario, lo que menciono arriba lo refuerza. Soy consciente de que promover la transcripción correcta del nombre es una difícil tarea, comparable sólo a la del cambio de al-Nubāhī por alBunnāhī. A pesar de recurrencia al nombre Išqalyūla en forma Išqaylūla, contradecir la lápida funeraria (que, insistamos, es de hecho la única fuente directa de la época de esta familia) sería muy difícil, si no imposible. Lo mismo se puede decir con respecto a los autores granadinos y los manuscritos más cercanos a ellos en el tiempo que han sobrevivido. En ninguna fuente encontraremos el más mínimo indicio de la vocalización en forma de Ašqīlūla, que actualmente se utiliza en la transcripción, o simplemente de que el nombre de la familia se escribiese con fatha en alif al comienzo de la palabra. En tal forma se trata de un neologismo artificialmente creado. Por el contrario, todos los manuscritos que tienen vocalización, completa o parcial, la contradicen. Teniendo en cuenta todos estos datos resulta, por lo tanto, necesario pronunciar y decir en este momento: Išqalyūla, no Ašqīlūla.

\footnotetext{
${ }^{60}$ IBN AL-JAṬīB, Lisān al-Dīn, al-Iḥạta fì ajbār Ġarnāta, ed. Muhammad 'Abd Allāh 'Inān, alQāhira 2001, vol. I, 342, 564, vol. III, 378, 382. Sin embargo, siempre es necesario tomar esta edición con máxima precaución por sus muchos defectos.

${ }^{61}$ RUBIERA MATA, María Jesús, "El significado del nombre de los Banū Ašqīlūla", en: AlAndalus 31,1 (1966) 378-379; RUBIERA DE EPALZA, María Jesús. "Los Banū Escallola, la dinastía granadina que no fue”, en Andalucía Islámica 2 (1981-82) 85-87.
} 


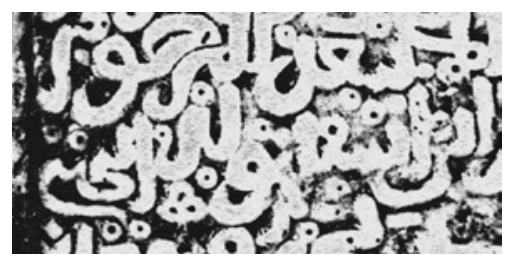

1. Deta lle de lápida funeraria de Abū al-Hasan Ibn 'Abd Allāh Ibn Išqalyūla.

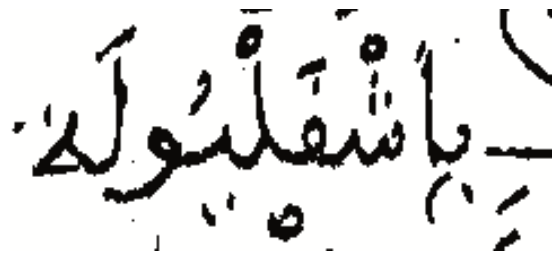

3. MS 1653 de Biblioteca de El Escorial fol. 37v.

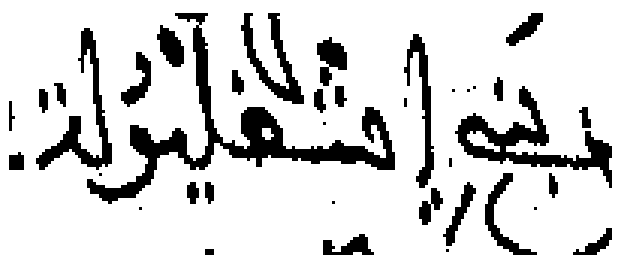

5. MS 1776 de Biblioteca de El Escorial fol. 91r.

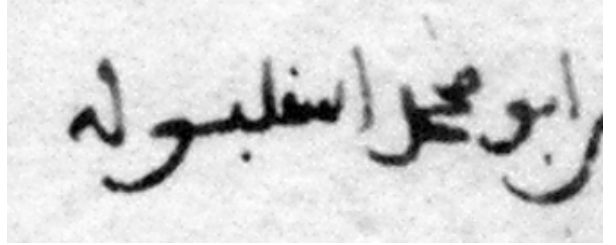

7. MS 1674 de Biblioteca de El Escorial p. 51

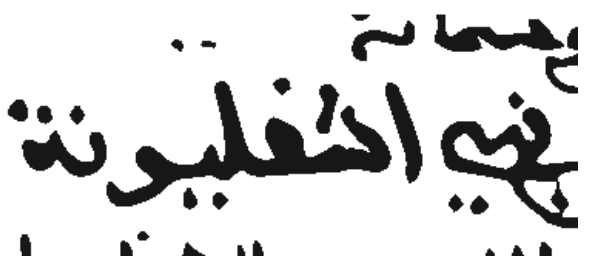

9. MS 205 de biblioteca de la Fundación del rey 'Abd al-

'Azīz en Casablanca p. 194 - error de copista - Išqalyūna

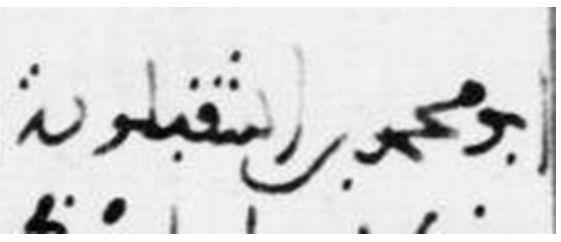

11. MS 7257 Biblioteca nacional de Francia fol. 56v, Išqablūla

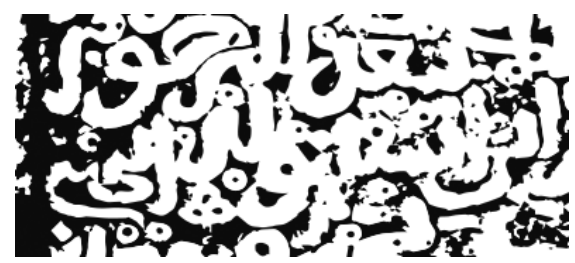

2. detalle de misma lápida en imagen vectorizado.

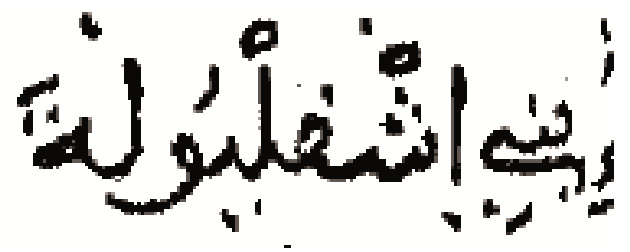

4. MS 1653 de Biblioteca de El Escorial fol. 38v.

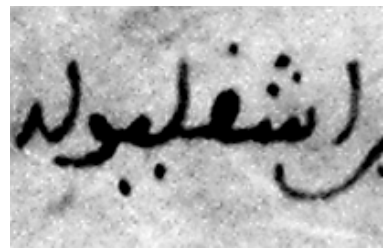

6. MS 1674 de Biblioteca de El Escorial p. 48

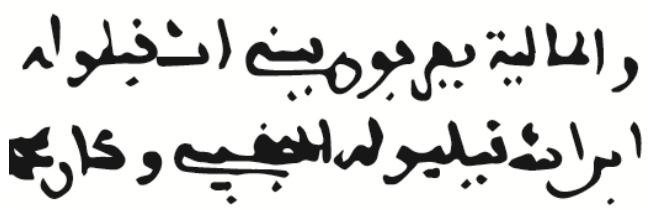

8. MS 205 de biblioteca de la Fundación del rey 'Abd al- 'Azīz en Casablanca p. 189 - errores de copista - Išqaylūla, Išqayliyūla

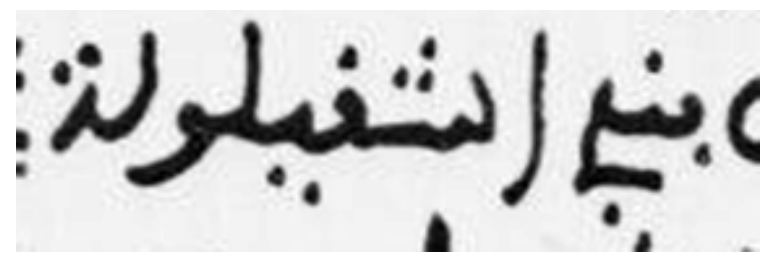

10. MS 7257 de Biblioteca nacional de Francia, fol. 116v, Išqaylūla

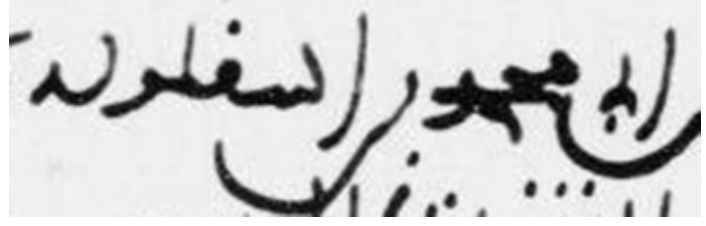

12. MS 7257 de Biblioteca nacional de Francia fol 106r, Isqalūla 